\title{
Volatility Estimation and Forecasting of EGX30
}

\author{
Mona Samy Elkhouly* \\ *Assistant Lecturer at Statistics, Mathematics and Insurance Department \\ Faculty of Commerce -Port Said University
}




\section{ملخص البحث}

من بين السمات الهامة للبيانات المالية التي حظيت باهتمام كبير هو ظاهرة التقلب (volatility) ؛

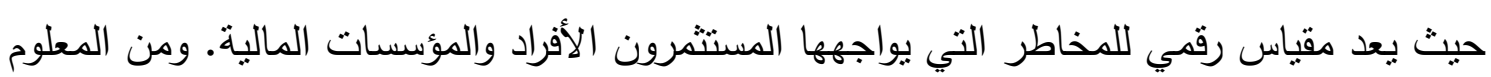
أن تقلبات البيانات المالية (volatility) كثيرا ما تتغير بمرور الوقت وتميل إلى التكتل في فترات (volatility clustering) والتقلبات المنخفضة يتبعها تقلبات منخفضة. هذه الظاهرة تتماشى مع التقلبات المتأرجحة. . ولقياس التقلبات نم اقتراح نماذج مختلفة للسلاسل الزمنية ودراستها. قدم Engle عام (1982) نماذج (ARCH) التي تفوقت على العديد من نماذج السلاسل الزمنية للانحدار الذاتي والمتوسطات المتحركة لأنها تسمح للتباينات الثرطية في بيانات السلاسل الزمنية أن تكون دالة محددة من الشاهدات التاريخية السابقة.

تم في هذه الدراسة مقارنه QMLE مع عدة توزيعات باستخدام بيانات العائد اليومي لاحد اهم المؤشرات المالية في سوق الأوراق المالية في الثرق الأوسط وهو EGX3. كما تم دراسة تأثثرات القيم المنطرفة على النمذجة والتتبؤ بالفروق المشروطة في سلاسل العودة مع هذه السلسلة. 


\section{ABSTRACT}

One of the significant features of financial data that has won much attention is the volatility; because it is a numerical measure of the risk faced by individual investors and financial institutions. It is well known that the volatility of financial data often varies over time and tends to cluster in periods, i.e., high volatility is usually followed by high volatility, and low volatility by low volatility.

The QML estimation procedure is illustrated with using daily return data for one stock in the Middle East Stock Exchange. The effects of outliers on modeling and forecasting the conditional variances in return series are also studied with this series. 


\section{INTRODUCTION}

The volatility of an asset or the volatility of the return of an asset plays an important role in managing risks in financial world. To measure the volatility, different time series models have been proposed and studied. Engle (1982) introduced the autoregressive conditional heteroscedasticity (ARCH) models. These models are superior to many conventional autoregressive-type and moving average-type time series models because they allow the conditional variances of the time series data to be a deterministic function of the past observations. Thereafter, a number of variations of ARCH models, such as the Generalized ARCH (GARCH), Exponential GARCH (EGARCH), Integrated GARCH (IGARCH), Fractionally Integrated GARCH (FIGARCH), Factor ARCH (FACTORARCH), Threshold GARCH (TGARCH), etc, were proposed to deal with a variety of data such as interest rates, exchange rates, equity returns, Treasury Bills, option pricing.

In this paper we provide an empirical study of GARCH models, namely GARCH $(1,1)$, using EGX 30 historical data and estimate the out ofsample forecast power.We also examine the stylized facts of financial time series .

(Franses, et al., 1999) examined the feature of excess kurtosis in the estimated residuals from GARCH models, even when conditional $t$ distributed errors is considered. They examined if this feature can be due to neglected additive outliers, where they focused on the out-of-sample forecasting properties of GARCH models for AO-corrected returns.

They proposed a method to detect AOs in GARCH models, and to reduce the impact of the AOs on parameter estimates and forecasts. They rewrote the GARCH model into the form of an ARMA model and took the same approach as (Chen, 1993) to handle additive outliers. They altered Bollerslev's GARCH model by assuming the asset returns follow a normal distribution with a possibility of additive outliers. They found that models for AO-corrected data yielded substantial improvement over GARCH and GARCH-t models for the original returns, and that this improvement holds for various samples. They showed that the forecasting performance of a GARCH model can be improved substantially when the impact of AOs is reduced, and that the GARCH model for AO-corrected returns also beats the GARCH-t model. 
The process by Francses and Ghijsels accounts only for additive outliers (Charles, et al., 2005) extended the Francses and Ghijsels additive outlier approach to robust estimation to include innovation outliers. They considered GARCH $(1,1)$ process as did Francses and Ghijsels. Charles and Darne used the same iteration approach to recalculate robust estimates of the returns to get better estimates of the GARCH process. They applied it to three daily stock market indexes and examined the effects of outliers on the diagnostics of normality. they applied the identification procedure of additive and innovative outliers in a GARCH model to three series Nasdaq100, Aex25, and Cac40.

\section{Definition [GARCH $(\mathbf{1}, \mathbf{1})$ ]}

In a $\operatorname{GARCH}(1,1)$, the variance $\left(\sigma_{\mathrm{t}}^{2}\right)$ is a function of an intercept $(\omega)$, a shock from the prior period $(\alpha)$ and the variance from the last period $(\beta)$ :

$$
\sigma_{\mathrm{t}}^{2}=\omega+\alpha_{1} \varepsilon_{\mathrm{t}-1}^{2}+\beta_{1} \sigma_{\mathrm{t}-1}^{2}
$$

Although volatility is not directly observable, it has some characteristics that are commonly seen in asset returns. These properties play an important role in the development of volatility models. Some of which are stated below:

\section{- Stylized fact 1:stationarity}

Time series of share prices pt are not stationary time series so we transform the original data by the log return.

Let $\mathrm{Pt}, \mathrm{t}=0 ; \ldots ; \mathrm{n}$, be a time series of prices of a financial asset, Instead of analyzing Pt, which often displays unit-root behavior and thus cannot be modeled as stationary, we often analyze log-returns on Pt, i.e. the series

$$
\mathrm{y}_{\mathrm{t}}=\log \mathrm{P}_{\mathrm{t}}-\log \mathrm{P}_{\mathrm{t}-1}=\log \left(\frac{\mathrm{P}_{\mathrm{t}}}{\mathrm{P}_{\mathrm{t}-1}}\right)=\log \left(1+\frac{\mathrm{P}_{\mathrm{t}}-\mathrm{P}_{\mathrm{t}-1}}{\mathrm{P}_{\mathrm{t}-1}}\right)
$$

\section{- $\quad$ Stylized fact 2: leptokurtic distribution}

Financial time series often exhibit leptokurtosis, which means that the distribution of their returns is fat-tailed. The GARCH model sometimes fails to capture the fat-tail property of financial data. This has led to the use of non-normal distributions to better model the fat-tailed characteristic. Kurtosis is computed as:

$$
k=\frac{1}{N} \sum_{i=1}^{N}\left(\frac{Y_{i}-\bar{Y}}{\hat{\sigma}}\right)^{4}
$$


equation (3) equals 3 for a normal distribution and above 3 for leptokurtosis, where the distribution is peaked relative to the normal distribution.

\section{- Stylized fact 3: Volatility clustering}

Large and small values in a log return series tend to occur in clusters. This indicates that there is dependence in the tails. (Mandelbrot, 1963) quoted "... large changes tend to be followed by large changes -of either sign- and small changes by small changes ...". This characteristic is called volatility clustering.

\section{The Empirical Study Data}

The natural frequency of data for GARCH estimator is daily data. weekly or monthly data can be used, but that smoothes some of the garchiness out of the data. GARCH with intraday data can also be used, but this gets complicated. There is seasonality of volatility throughout the day. The seasonality highly depends on the particular market where the trading happens, and possibly on the specific asset.

In this empirical study Six years of daily returns for a major middle east financial markets EGX30 indicex in the period between 1/1/2012 and $19 / 1 / 2018$ is used. In this study a comparison of QMLE with several fat tailed distributions for $\operatorname{GARCH}(1,1)$ with $\mu=0$ process is performed in order to assess the performance of QMLE in estimating and forecasting the parameters and the volatility of the $\operatorname{GARCH}(1,1)$ model.

The EGX 30 Index is a free-float capitalization weighted index of the 30 most highly capitalized and liquid stocks traded on the Egyptian Exchange. EGX 30 constituents are reviewed and changed twice a year (end of January and end of July). The index was developed with a base level of 1000 as of January 1st 1998 and previously named CASE 30 Index.

\section{Steps of Conducting the Empirical Study Exploratory Data Analysis}

In this stage the following steps are conducted:

\section{Step 1: Testing Stationarity}

Figure1 shows a plot of the daily closing price of EGX30. It is observed that the EGX 30 series has a trend, i.e. the mean is obviously non-constant over time. hence it is to be considered as a 
non-stationary time series. This is typical for financial time series. such trends in financial time series are nearly impossible to predict, and difficult to characterize mathematically. Hence, it is difficult to perform statistical analysis on the prices or index values, which will be denoted by $\mathrm{P}_{\mathrm{t}}$

based on the results of the skewness of the stocks, most of the returns seem to be skewed. Due to this, the estimation procedure of this study uses the Student-t distribution and the Generalized Error distribution and there skewed versions in the estimation with QMLE.

EGX 30 Stock Price

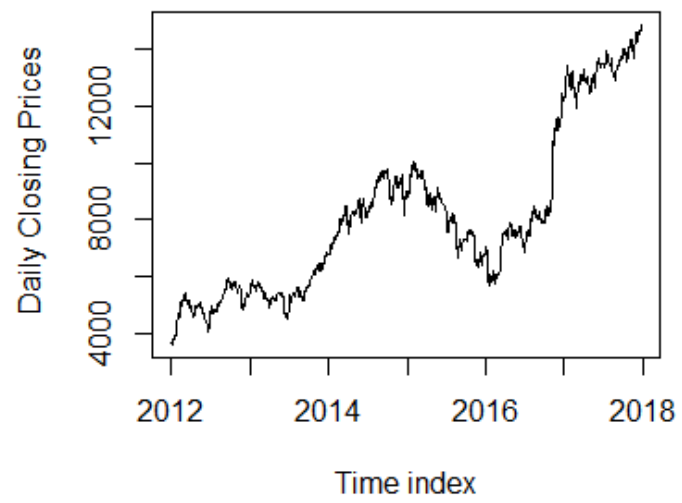

Figure 1 plot of the daily closing price of the EGX 30

In order to convert non-stationary series to stationary, differencing method can be used In financial time series, it is often that the series is transformed by logging and then the differencing is performed. This is because financial time series is usually exposed to exponential growth, and thus log transformation can smooth out "linearize" the series and differencing will help stabilize the variance of the time series. in statistical analysis of financial data, $\log$ returns $r_{t}$ is usually considered. 


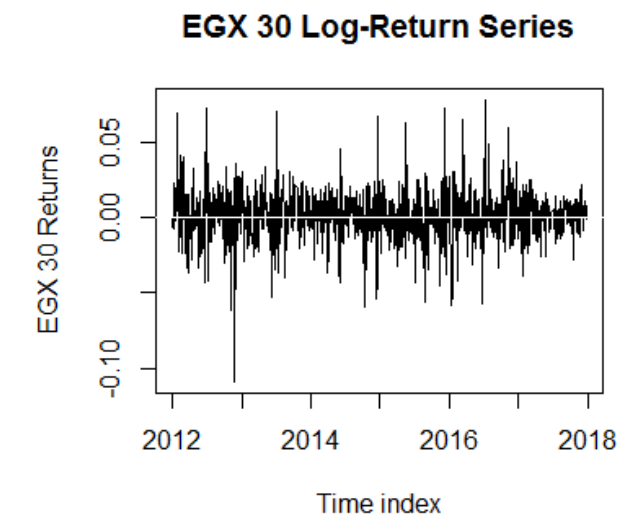

Figure 2 plot of the Log Return of EGX30

The plot in Figure 2 shows some common features that are very typical for financial data.

- Nearly uncorrelated log-returns with a mean close to zero.

- Clusters of volatility, i.e. periods where log returns are either big or small

- Some extreme spikes, i.e. outliers that correspond to very big or small returns

- The return series is stationary so we can model the return series.

\section{Step 2: Testing Normality}

(Bollerslev, 1987) and (Nelson, 1991) addressed characteristic of excess kurtosis in financial time-series data and hence, a normal distribution does not correctly describe the data. It is also known that stock index returns exhibit negative skewness (GLOSTEN, et al., 1993). To test the data for normality, and see if the same properties are present in this thesis data, summary statistics table is examined and Q-Q plots of the return and a (Jarque, et al., 1987) test was performed. A normal distribution is symmetric/ mesokurtic, when it has a coefficient of kurtosis equal to 3 . financial time series also often show tendencies to be leptokurtic

\section{- Summary Statistics}

In table 1the mean is close to zero, as expected since daily data is used and there is no time for a return to occur. Also, the table presents skewness and kurtosis. The kurtosis is much larger than 3 which is the kurtosis of a standard normal, in other words all return series exhibit fat tails. Notable, 
the skewness is negative for five series which is a common characteristic of financial time series.

Table 1 Summary Statistics for EGX30

\begin{tabular}{|c|c|c|c|c|c|c|c|c|}
\hline & $\mathbf{n}$ & mean & sd & min & max & range & skew & kurtosis \\
\hline EGX 30 & 1315 & $1.06 \mathrm{E}-03$ & 0.0157691 & -0.108647 & 0.0780619 & 0.1867085 & -0.087023 & 4.793113 \\
\hline
\end{tabular}

\section{- Quantile-Quantile plot (Q-Q)}

normal Quantile-Quantile plots serve for verifying the (Gaussian) distributional assumption. It can also be used to test if data follows other theoretical distributions. If the data follows the theoretical distribution, then the points in the Q-Q Plot lie on a straight line.

EGX 30 Normal Plot of Log Returns

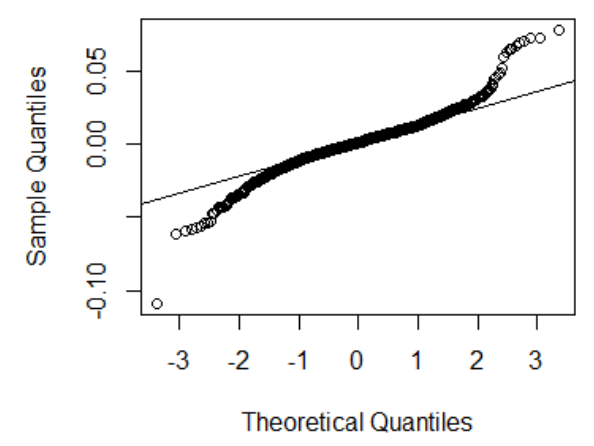

Figure 3 Q-Q plot of the Log Returns of EGX30

Q-Q plots shows clearly that even the fitted normal distribution does not provide a good fit as a reference distribution. The empirical distribution of the daily returns exhibits significantly heavier tails than the reference distribution which implies that another choice of parametric family should be considered. it can be concluded that the data is not normally distributed and a fat tailed distribution should be considered for all series.

\section{- The Jarque-Bera test}

The Jarque-Bera test determines if a sample has an excess kurtosis and a skewness equal to zero or not, i.e. whether the sample is normally distributed or not. The test static is:

$$
\mathrm{JB}=\frac{\mathrm{n}}{6}\left[\mathrm{~S}^{2}+\frac{(\mathrm{K}-3)^{2}}{4}\right]
$$


Where $\mathrm{n}$ is the number of observations, $\mathrm{S}$ is the skewness and $\mathrm{K}$ is the kurtosis. The excess kurtosis is defined as the term $\mathrm{EK}=\mathrm{K}-3$, since the normal distribution has a kurtosis equal to three. A distribution with thick tails has a positive excess kurtosis, in other words it has a higher peak. In that case, it is said to be leptokurtic. The sample kurtosis is calculated as:

$$
\mathrm{K}=\frac{1}{\mathrm{n}} * \frac{\sum_{\mathrm{i}=1}^{\mathrm{n}}\left(\mathrm{x}_{\mathrm{i}}-\overline{\mathrm{x}}\right)^{4}}{\left(\hat{\sigma}^{2}\right)^{2}}
$$

And the sample skewness is expressed as:

$$
\mathrm{S}=\frac{1}{\mathrm{n}} * \frac{\sum_{\mathrm{i}=1}^{\mathrm{n}}\left(\mathrm{x}_{\mathrm{i}}-\overline{\mathrm{x}}\right)^{3}}{\left(\hat{\sigma}^{2}\right)^{3 / 2}}
$$

Where $\hat{\sigma}^{2}$ is defined as:

$$
\hat{\sigma}^{2}=\frac{1}{n} * \sum_{i=1}^{n}\left(x_{i}-\bar{x}\right)^{3}
$$

Given this, the hypotheses of the Jarque-Bera test are:

$\mathrm{H}_{0}: \mathrm{S}=\mathrm{EK}=1$

$\mathrm{H}_{\mathrm{a}}: \mathrm{S} \neq 1$ or $\mathrm{EK} \neq 0$

The null hypothesis is that the distribution is normal, and if it is false that indicates a non-normal distribution. Any deviation from the relationship stated in the null hypothesis increases the JB-statistic. The Jarque-Bera test static JB can be compared with a chi-square distribution with two degrees of freedom, and is rejected if the observed value exceeds the critical value given by the distribution of $\chi^{2}$ with two degrees of freedom. For an $\alpha=0$. 05 the critical value equal 5.99. The Jarque-Bera test of normality compares the sample skewness and kurtosis to 0 and 3, their values under normality. The null hypothesis states that distribution of the series is symmetric and mesokurtic, which implies that a rejection is in place if the residuals from the model is skewed or leptokurtic

Table 2 Jarque-Bera test of normality

\begin{tabular}{|l|l|}
\hline Jarque-Bera & EGX 30 \\
\hline X-squared & 1266.68 \\
\hline
\end{tabular}

where $\mathrm{df}=2, \mathrm{p}$-value $<2.2 \mathrm{e}-16$ the null hypothesis of a Gaussian distribution is rejected. 


\section{Step 3: Testing for Autocorrelation}

Through ACF plot of return and squared returns and by using Ljung-Box test. First, The Sample Autocorrelation function is a very useful tool and can be used for checking for serial correlation in the return data. the autocorrelation function (ACF) of the log returns addresses the issue of uncorrelatedness. Second, the dependency in the conditional variance of the process can be captured by showing the ACF of the squared log returns. In particular, whenever volatility clusters do exist, the squared log returns will show autocorrelation. The left upper plot in the following plots shows the Sample Autocorrelation Function for the daily returns of lags 0 to 30 . Based on inspection of the Sample Autocorrelation Function plot it is not completely clear whether the data is serially correlated or not, even though it has minor significant serial correlation at few lags. The right upper plot of the following plots shows the Sample Autocorrelation Function for the daily squared returns. The lower right plot in the following plots shows the Sample Partial Autocorrelation Function which shows clearly significant autocorrelation and thus confirms that the squared returns are serially correlated
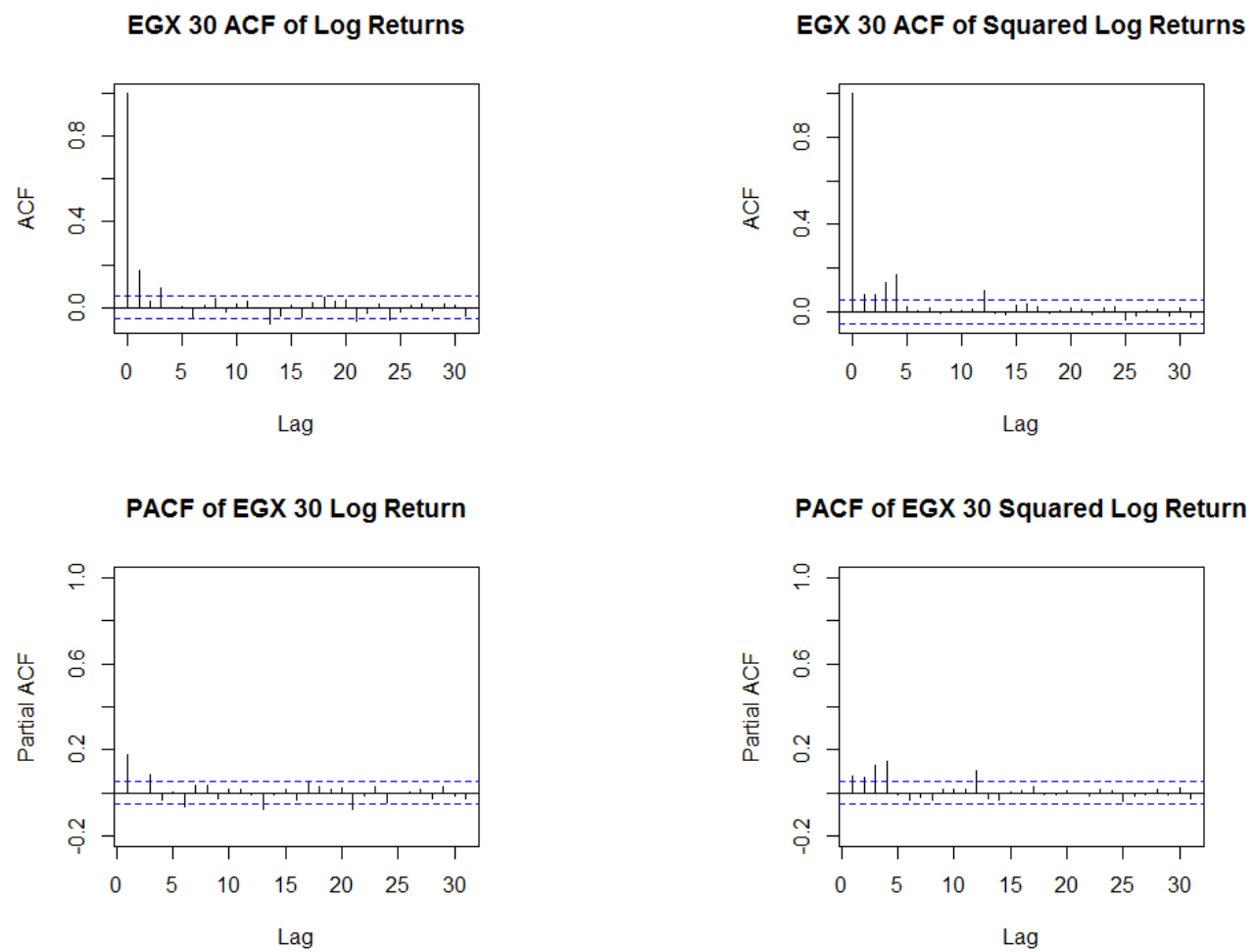

Figure 4 Autocorrelation and partial Autocorrelation of EGX30 log returns and squared $\log$ returns 


\section{- The Ljung-Box test}

The Ljung-Box test determines the degree of autocorrelation for a given lag length. The hypotheses are:

$\mathrm{H}_{0}: \rho_{1}=\rho_{2}=\cdots=\rho_{\mathrm{k}}$

$H_{a}$ : at least one of $\rho_{k} \neq 0$

The test function has the following form:

$$
\mathrm{Q}=\mathrm{n}(\mathrm{n}+2) \sum_{\mathrm{k}=1}^{\mathrm{h}} \frac{\hat{\rho}_{\mathrm{k}}^{2}}{\mathrm{n}-\mathrm{k}}
$$

Where $\mathrm{n}$ is the sample size, $\mathrm{h}$ the number of lags and $\mathrm{k}$ the lag length at a certain point in the summation. the results from this test are presented, studied at various lag lengths.

the Ljung-Box Q-test null hypothesis that all autocorrelations up to the tested lags are zero is rejected for lags 5, 10 and 15 at a 5\% significance level.

Table 3 Ljung-Box Test Results

\begin{tabular}{|c|c|c|}
\hline Ljung-Box & X-squared & p-value \\
\hline EGX 30 & 53.239 & $6.722 \mathrm{e}-08$ \\
\hline
\end{tabular}

The $\mathrm{p}$ value is low. Therefore we can reject the null hypothesis (no serial correlation) and say that there is serial correlation in the log returns

\section{Step 4: Testing for Significance of Expected Log-Return}

$\mathrm{T}$ test is used to find the expected log-return and to test if the mean return is zero with a t-test. for the t-test the Null is Mean Equals Zero while the alternative hypothesis states that the true mean is not equal to 0

Table $4 \mathrm{t}$-test for significance of expected log-return

\begin{tabular}{|l|l|l|}
\hline INDEX & t-value & p-value \\
\hline EGX 30 & 2.3217 & 0.05041 \\
\hline
\end{tabular}

The results give a high $\mathrm{p}$ value. so the null cannot be rejected at $95 \%$ confidence level. Therefore the expected log-return is not significantly different from zero.

\section{Step 5: Testing for Significance of Squared Log-Return}

Test if the mean squared return is zero with a t-test. The results give a low $\mathrm{p}$ value so we can conclude that squared returns are statistically 
significantly different from zero, hence we need to model the variance equation using an ARCH or GARCH model.

Table $5 \mathrm{t}$-test for significance of squared log-return

\begin{tabular}{|c|c|c|}
\hline INDEX & t-value & p-value \\
\hline EGX 30 & 13.776 & $2.20 \mathrm{E}-16$ \\
\hline
\end{tabular}

\section{Step 6: Testing for Arch Effect}

The ARCH-LM test investigates whether the proposed data contain any variation in the conditional volatilities. It determines whether the GARCHmodel is suitable. LM is an abbreviation for Lagrange Multiplier.

This is determined through regressing the squared returns $r_{t}^{2}$ :

$$
\mathrm{r}_{\mathrm{t}}^{2}=\alpha_{0}+\left(\sum_{\mathrm{i}=1}^{\mathrm{n}} \alpha_{\mathrm{i}} * \mathrm{r}_{\mathrm{t}-\mathrm{i}}^{2}\right)+\varepsilon_{\mathrm{t}}
$$

Given that $r_{t}=\sigma_{t} * z_{t}$. The ARCH-LM test has the null hypothesis of whether all the coefficients in the previous regression are zero, there are no ARCH-effects.

The hypotheses are:

$\mathrm{H}_{0}: \alpha_{1}=\alpha_{2}=\cdots=\alpha_{\mathrm{n}}=0$

Ha : at least of of $\alpha_{n} \neq 0$

The null hypothesis states that there is homoscedasticity in the variance. In other words, there is no volatility clustering in the series.

The term $\mathrm{T}$ denotes the sample size. LM is $\chi^{2}$ distributed. A desired outcome is a significant statistic, indicating that there is a significant ARCH-effect in the log return. It is clear from Table that shows LM test result that all returns have highly significant $p$-values which shows that there is ARCH effect present in the data.

Table 6 ARCH-LM Test Results

\begin{tabular}{|c|c|c|}
\hline INDEX & Chi-squared & p-value \\
\hline EGX 30 & 70.497 & $2.59 \mathrm{E}-10$ \\
\hline
\end{tabular}

\section{Step 7: Determining the Order of $\operatorname{GARCH}(\mathbf{p}, \mathbf{q})$}

An essential task in modeling volatility using GARCH models is the determination of the ARCH order $\mathrm{p}$ and $\mathrm{GARCH}$ order $(\mathrm{p}, \mathrm{q})$ for a particular series. Considering GARCH models is similarly done as ARMA models using residuals and classical model selection criteria such as the 
Akaike information criterion (AIC) and the Schwartz-Bayesian information criterion (BIC) can be employed for choosing models. The $\mathrm{R}$ software package is employed to compute the AIC to determine best fitting model. Generally, GARCH models with $\mathrm{p}, \mathrm{q} \leq 2$ are typically selected by AIC and BIC. In the Error! Reference source not found. below smaller AIC is an indication of an appropriate model. Therefore, since GARCH $(1,1)$ has the smallest AIC among the contesting models we consider it as the appropriate model. GARCH orders and parameters are selected based on AIC for an initial GARCH fit.

To investigate this, $\operatorname{ARCH}(q)$ and $\operatorname{GARCH}(p, q)$ models were fitted where $p$ were allowed to vary from 0 to 4 while q were allowed to vary from 0 to 5 . The orders for $\mathrm{p}$ and $\mathrm{q}$ were selected based on the lowest AIC value. Error! Reference source not found.Table 7 shows that For EGX 30 the GARCH(1,1) model was found to be the best.

Table 7 Determining the order of $\operatorname{GARCH}(p, q)$

\begin{tabular}{|c|c|c|}
\hline \multicolumn{2}{|c|}{ GARCH ORDER } & EGX30 \\
\hline $\mathbf{p}$ & $\mathbf{q}$ & aic \\
\hline 0 & 0 & -6548.72 \\
\hline 0 & 1 & -6566.82 \\
\hline 0 & 2 & -6590.03 \\
\hline 0 & 3 & -6603.2 \\
\hline 0 & 4 & -6650.74 \\
\hline 0 & 5 & -6644.97 \\
\hline 1 & 0 & -6548.72 \\
\hline 1 & 1 & -8504.17 \\
\hline 1 & 2 & -6648.56 \\
\hline 1 & 3 & -6642.82 \\
\hline 1 & 4 & -6653.19 \\
\hline 1 & 5 & -6641.05 \\
\hline 2 & 0 & -6548.72 \\
\hline 2 & 1 & -6650.3 \\
\hline 2 & 2 & -6651.8 \\
\hline 2 & 3 & -6640.41 \\
\hline 2 & 4 & -6648.97 \\
\hline 2 & 5 & -6640.54 \\
\hline 3 & 0 & -6548.72 \\
\hline 3 & 1 & -6650.3 \\
\hline 3 & 2 & -6651.8 \\
\hline 3 & 3 & -6640.41 \\
\hline 3 & 4 & -6648.97 \\
\hline 3 & 5 & -6640.54 \\
\hline & & \\
\hline
\end{tabular}




\begin{tabular}{|c|c|c|}
\hline 4 & 0 & -6548.72 \\
\hline 4 & 1 & -6650.3 \\
\hline 4 & 2 & -6651.8 \\
\hline 4 & 3 & -6640.41 \\
\hline 4 & 4 & -6648.97 \\
\hline 4 & 5 & -6640.54 \\
\hline
\end{tabular}

\section{Estimation of the GARCH $(1,1)$ Model}

A non-robust estimator; quasi-maximum likelihood (QMLE) estimator with four different fat tailed distributions is used in this study. When fitting a GARCH-model based on financial data the conditional distribution of the returns has to be defined. Earlier, in table 1 the skewness and kurtosis of the studied stocks are presented, and the results show that all of the stocks kurtosis exceeds the normal distributions kurtosis of three. Studies illustrate that returns are not normally distributed. Instead, the Student-t distribution or the Generalized Error distribution captures the observed kurtosis in empirical returns in a more sufficient way than the normal distribution. Judging by the results of the skewness of the stocks in Table 1, the return seems to be skewed. Due to this, the estimation procedure of this study uses the Student-t distribution and the Generalized Error distribution and there skewed versions in the estimation with QMLE.

\section{Evaluation of In-Sample Fit}

In this study four criteria will be used, the Akaike (AIC), Bayesian (BIC), Hannan-Quinn (HQIC) and Shibata (SIC) information criteria to enable model selection.

When comparing the in-sample fit of different models using the information criteria tests the smaller value of the criterion the better. A model with a smaller $t$ test criteria provides the best in-sample fit The criteria is given by:

$$
\begin{aligned}
& \mathrm{AIC}=\frac{-2 \mathrm{LL}}{\mathrm{N}}+\frac{2 \mathrm{M}}{\mathrm{N}} \\
& \mathrm{BIC}=\frac{-2 \mathrm{LL}}{\mathrm{N}}+\frac{\mathrm{Mlog}(\mathrm{N})}{\mathrm{N}} \\
& \mathrm{HQIC}=\frac{-2 \mathrm{LL}}{\mathrm{N}}+\frac{(2 \mathrm{Mlog}(\log (\mathrm{N}))}{\mathrm{N}}
\end{aligned}
$$




$$
\mathrm{SIC}=\frac{-2 \mathrm{LL}}{\mathrm{N}}+\log \left(\frac{(\mathrm{N}+2 \mathrm{M})}{\mathrm{N}}\right)
$$

In table 8 the information criteria results are summarized. From the table, it can be seen that GARCH models with the skewed student $-t$ distribution perform very well and therefore recommended for financial time series in QMLE estimation in case of EGX30

Table 8 Information Criteria For GARCH(1,1)

\begin{tabular}{|c|c|c|c|c|}
\hline DIST & $\begin{array}{c}\text { QMLE } \\
\text { std }\end{array}$ & $\begin{array}{c}\text { QMLE } \\
\text { GED }\end{array}$ & $\begin{array}{c}\text { QMLE } \\
\text { sstd }\end{array}$ & $\begin{array}{c}\text { QMLE } \\
\text { sGED }\end{array}$ \\
\hline Akaike & -26.5418 & -26.2912 & $\mathbf{- 2 4 . 0 7 7 7}$ & -25.6108 \\
\hline Bayes & -26.5586 & -26.308 & $\mathbf{- 2 4 . 0 9 8 7}$ & -25.6318 \\
\hline Shibata & -26.5418 & -26.2912 & $\mathbf{- 2 4 . 0 7 7 7}$ & -25.6107 \\
\hline Hannan-Quinn & -26.5482 & -26.2975 & $\mathbf{- 2 4 . 0 8 5 6}$ & -25.6187 \\
\hline
\end{tabular}

\section{Forecasting with the GARCH $(1,1)$ Model}

Let $\mathrm{T}$ to be the forecast origin. Then the single-step ahead forecast for $\varepsilon_{T+1}^{2}$ is

$$
\varepsilon_{T}^{2}(1)=\widehat{\omega}+\hat{\alpha} \varepsilon_{T}^{2}+\hat{\beta} \varepsilon_{T}^{2}
$$

Since $\varepsilon_{T}^{2}=\sigma_{T}^{2} z_{T}^{2}$ the $\operatorname{GARCH}(1,1)$ model can be re-written as

$$
\begin{gathered}
\sigma_{T}^{2}(1)=\omega+\alpha \varepsilon_{T-1}^{2}+\beta \sigma_{T-1}^{2} \\
\sigma_{T}^{2}(1)=\omega+(\alpha+\beta) \sigma_{T-1}^{2}+\alpha \sigma_{T-1}^{2}\left(z_{T-1}^{2}-1\right)
\end{gathered}
$$

so that at time $\mathrm{T}+2$, we have

$$
\sigma_{T+2}^{2}=\omega+(\alpha+\beta) \sigma_{T+1}^{2}+\alpha \sigma_{T-1}^{2}\left(z_{T+1}^{2}-1\right)
$$

with $E\left(\left(z_{T+1}^{2}-1\right) \mid \mathcal{F}_{T}\right)=0$. Therefore the $2-$ step ahead forecast is

$$
\sigma_{T}^{2}(2)=\widehat{\omega}+(\hat{\alpha}+\hat{\beta}) \sigma_{T}^{2}(1)
$$

In general, the $l-$ step ahead forecast for $\sigma_{T+1}^{2}$ is

$$
\sigma_{T}^{2}(l)=\widehat{\omega}+(\hat{\alpha}+\hat{\beta}) \sigma_{T}^{2}(l-1)
$$

for $l>1$.

By repeated substitution of $\left(\sigma_{T}^{2}(l)\right)$ the $l$ - step ahead forecast for GARCH $(1,1)$ can be expressed as

$$
\sigma_{T}^{2}(l)=\widehat{\omega}+(\hat{\alpha}+\hat{\beta})^{l-1}\left(\sigma_{T}^{2}(1)-\hat{\sigma}^{2}\right)
$$

for $l>1$, where

$$
\hat{\sigma}^{2}=\frac{\widehat{\omega}}{1-\hat{\alpha}-\hat{\beta}}
$$


The expression shows that $\sigma_{\mathrm{T}}^{2}(\mathrm{l}) \rightarrow \hat{\sigma}^{2}$ as $\mathrm{l} \rightarrow \infty$, provided that $(\hat{\alpha}+\hat{\beta})<$ 1 so as the forecast horizon goes to infinity, the variance forecast approaches the unconditional variance of The multi-step ahead forecast of a GARCH $(1,1)$ model converges to the unconditional variance of $\varepsilon_{t}$ as the forecast horizon goes to infinity provided that the variance of $\varepsilon_{t}$ exists [Tsay, 2010]. It is often useful not only to forecast next period's variance of returns, but also to make an 1-step ahead forecast, especially if our goal is to price an option with 1 steps to expiration using our volatility model.

\section{Evaluating the Forecasts}

The evaluation of volatility forecasts raises the problem that the variable of interest is latent and cannot be directly compared with the true variance for that certain period. The reason is that the instantaneous volatility cannot be observed (Andersen, et al., 1998). This problem can be solved by replacing the latent conditional variance by a proxy for the true volatility.

In GARCH model the conditional variance is the object of study and the variance is considered completely time varying and thus should be able to take different values at each time point. If only daily closing prices are available the only volatility proxy that fully emphasizes the time 24 varying property is the daily squared returns. The daily squared returns have been used as the proxy for the unobserved variance , (Cumby, et al., 1993), (Figlewski, 1997).

Squared returns are however an extremely noisy proxy of the latent realized variance and The use of daily squared returns as a proxy led to very poor out-of-sample performance in spite of highly significant in-sample fitting, see (Andersen, et al., 1998). This led to the conclusion that the volatility models explained very little of the time variability of the volatility and thus had limited practical value.

However (Andersen, et al., 1998) showed that GARCH type volatility provides accurate volatility forecasts when the out of sample forecasting performance was evaluated with a more suited proxy. The proposed proxy was to estimate the daily volatility using cumulative squared intra-day returns. The intra-day returns are used as a proxy for the volatility in the following manner. Assume there are $\mathrm{m}$ equally spaced observations per trade day and denote the ith intra-day return during day $t$ by $r_{i, m, t}$. The cumulative squared intra-day returns are then computed as 


$$
\hat{\sigma}_{\mathrm{RV}, \mathrm{m}, \mathrm{t}}^{2}=\sum_{\mathrm{i}=1}^{\mathrm{m}} \mathrm{r}_{\mathrm{i}, \mathrm{m}, \mathrm{t}}^{2}
$$

If $m=1$ the cumulative squared intra-day return proxy is equal to the daily squared return proxy. With $m=1$ the proxy is unbiased but very noisy. As $\mathrm{m} \rightarrow \infty \hat{\sigma}_{\mathrm{RV}, \mathrm{m}, \mathrm{t}}^{2} \stackrel{\mathrm{p}}{\rightarrow} \sigma_{\mathrm{t}}^{2}$ where $\sigma_{\mathrm{t}}^{2}$ denotes the true latent volatility. However, using the cumulative squared intra-day returns as a proxy for the realized daily volatility requires high frequency data which in many cases aren't available.

Reliable open and close prices and intraday high and low prices are often available for most financial assets over long time horizons. There are volatility proxies that use such data instead of the high frequency data to estimate the volatility. In this empirical study only daily data was available resulting in that another proxy than the cumulative squared intra-day return proxy had to be used. A simplified proxy will be used, first introduced by Parkinson (1980) usually referred to as the High-Low range proxy. The high low range at day $t$ denoted $R G_{t}$ is defined as

$$
\mathrm{RG}_{\mathrm{t}}=\max _{\tau}\left(\log \left(\mathrm{P}_{\tau}\right)\right)-\min _{\tau}\left(\log \left(\mathrm{P}_{\tau}\right)\right)
$$

where $\mathrm{P}_{\tau}$ is the price level at time $\tau$ during the day. The log range is thus the difference of the logarithm of the highest price level during the given day and the logarithm of the lowest price during the same day. This range contains more information than the simple daily return based on the closing price since it incorporates how the price has fluctuated throughout the day. For example, on a day when the price fluctuates substantially during the day but the closing price still is close to the opening price, the daily return would suggest a day of low volatility while the log range would reflect the intraday price movements and thus imply correctly that the volatility was high. Assuming a geometric Brownian motion with zero drift and with a constant volatility $\sigma$ the expected value of the squared log range is directly related to the volatility of the process by the following expression

$$
\mathrm{E}_{\mathrm{t}-1}\left[\mathrm{RG}_{\mathrm{t}}^{2}\right]=4 * \log (2) * \sigma_{\mathrm{t}}^{2}
$$

Hence, the Parkinson estimator for the volatility denoted $\hat{\sigma}_{\mathrm{p}, \mathrm{t}}^{2}$ is defined by

$$
\hat{\sigma}_{\mathrm{p}, \mathrm{t}}^{2}=\frac{\left[\log \left(\mathrm{H}_{\mathrm{t}}\right)-\log \left(\mathrm{L}_{\mathrm{t}}\right)\right]^{2}}{4 * \log (2)}
$$


where $H_{t}, L_{t}$ denote the daily high and low price respectively. An extension to Parkinson's volatility estimator was provided by Garman and Klass (1980) which in addition to the daily high and low prices also utilized the information in the opening and closing prices. The estimator is defined as

$$
\hat{\sigma}_{\mathrm{GK}, \mathrm{t}}^{2}=0.5 * \log \left(\frac{\mathrm{H}_{\mathrm{t}}}{\mathrm{L}_{\mathrm{t}}}\right)^{2}-(2 * \log (2)-1) * \log \left(\frac{\mathrm{C}_{\mathrm{t}}}{\mathrm{O}_{\mathrm{t}}}\right)^{2}
$$

where $\mathrm{H}_{t}, \mathrm{~L}_{\mathrm{t}}$ denote the daily high and low price respectively and $\mathrm{C}_{t}, \mathrm{O}_{t}$ denote the closing and opening price respectively. Under idealized conditions the Garman-Klass volatility estimator is a less noisy proxy than the Parkinson estimator. However empirical studies have shown that the Parkinson's estimator performs well with real data, see Chou et al. (2010) and Alizadeh, Brandt and Diebold (2002). In addition the Parkinson's estimator appears to be very robust to market microstructure effects, see Brandt and Diebold (2006). For these reasons the Parkinson's estimator will be used as the proxy for the volatility in this study.

\section{- $\operatorname{GARCH}(1,1)$ Forecast Evaluation}

With the volatility proxy, $\hat{\sigma}_{\mathrm{p}, \mathrm{t}}^{2}$, and the 1 day ahead volatility forecasts, $h_{t-1}^{2}$ (1) computed for each of the days in the out-of-sample period it is important to evaluate the performance of the respective volatility models which The preferences are usually expressed through a loss function.

The following loss functions will be used in the models out-of-sample forecast performance evaluation

$$
\begin{aligned}
& \text { MSE }=\mathrm{n}^{-1} \sum_{\mathrm{t}=1}^{\mathrm{n}}\left(\hat{\sigma}_{\mathrm{p}, \mathrm{t}}^{2}-\mathrm{h}_{\mathrm{t}-1}^{2}(1)\right)^{2} \\
& \text { Qlike }=\mathrm{n}^{-1} \sum_{\mathrm{t}=1}^{\mathrm{n}}\left(\log \left(\mathrm{h}_{\mathrm{t}-1}^{2}(1)\right)+\hat{\sigma}_{\mathrm{p}, \mathrm{t}}^{2} \mathrm{~h}_{\mathrm{t}-1}^{-2}(1)\right) \\
& \mathrm{R}^{2} \mathrm{LOG}=\mathrm{n}^{-1} \sum_{\mathrm{t}=1}^{\mathrm{n}}\left[\log \left(\hat{\sigma}_{\mathrm{p}, \mathrm{t}}^{2} \mathrm{~h}_{\mathrm{t}-1}^{-2}(1)\right)\right]^{2} \\
& \text { MAE }=\mathrm{n}^{-1} \sum_{\mathrm{t}=1}^{\mathrm{n}}\left|\hat{\sigma}_{\mathrm{p}, \mathrm{t}}-\mathrm{h}_{\mathrm{t}-1}(1)\right| \\
& \text { PSE }=\mathrm{n}^{-1} \sum_{\mathrm{t}=1}^{\mathrm{n}}\left(\hat{\sigma}_{\mathrm{p}, \mathrm{t}}^{2}-\mathrm{h}_{\mathrm{t}-1}^{2}(1)\right)^{2} \mathrm{~h}_{\mathrm{t}-1}^{-4}(1)
\end{aligned}
$$

where $n$ is the number of days in the out-of-sample period, $\hat{\sigma}_{p, t}^{2}$ is the volatility proxy at day $\mathrm{t}$ and $\mathrm{h}_{\mathrm{t}-1}^{2}(1)$ is the one day ahead volatility forecast at time $\mathrm{t}-1$. 
Table 9 loss functions results for $\operatorname{GARCH}(1,1)$ forecast evaluation

\begin{tabular}{|c|c|c|c|c|}
\hline $\begin{array}{c}\text { DIST } \\
\text { INFO }\end{array}$ & $\begin{array}{c}\text { QMLE } \\
\text { std }\end{array}$ & $\begin{array}{c}\text { QMLE } \\
\text { GED }\end{array}$ & $\begin{array}{c}\text { QMLE } \\
\text { sstd }\end{array}$ & $\begin{array}{c}\text { QMLE } \\
\text { sGED }\end{array}$ \\
\hline MSE & $7.05 \mathrm{E}-10$ & $\mathbf{6 . 0 5 E}-10$ & $1.47 \mathrm{E}-09$ & $7.33 \mathrm{E}-10$ \\
\hline MAD & $2.57 \mathrm{E}-06$ & $\mathbf{2 . 3 8 E - 0 6}$ & $3.71 \mathrm{E}-06$ & $2.62 \mathrm{E}-06$ \\
\hline R2LOG & 0.067456 & $\mathbf{0 . 0 6 3 9 3}$ & 0.086047 & 0.068358 \\
\hline PSE & 0.008116 & $\mathbf{0 . 0 0 8 0 2 9}$ & 0.008468 & 0.008137 \\
\hline Q-LIKE & -0.07534 & $\mathbf{- 0 . 0 7 5 9 6}$ & -0.07228 & -0.07518 \\
\hline
\end{tabular}

\section{Conclusion and Recommendations}

The QMLE method is non-robust to the presence of outliers even with fattailed and skewed distributions.

Stock market data comes along with some skewness, tail weights, outliers and unknown distributions that violates some underlying assumptions for which the estimates from QMLE is efficient. Since QMLE estimates is sensitive to outliers, then QMLE estimation for the GARCH coefficient will be biased and not efficient. Such evidence provides a clear motivation for exploring the use of a more robust method for estimation of GARCH coefficients. 


\section{References}

Andersen, T. G., \& Bollerslev, T. (1998). Answering the skeptics: Yes, standard volatility models do provide accurate forecasts. International Economic Review , 39, 885-907.

Bollerslev, T. (1987). A Conditionally Heteroskedastic Time Series Model for Speculative Prices and Rates of Return. The Review of Economics and Statistics , 69 (3), 542-547.

Carnero, P. a. (2007). EFFECTS OF OUTLIERS ON THE IDENTIFICATION AND ESTIMATION OF GARCH MODELS. Time Series Analysis , 28 (4), 471-497.

Charles, A., \& Darne, O. (2005). Outliers and GARCH models in financial data. Economics Letters , 86 (3).

Chen, C. L. (1993). Forecasting time series with outliers. J. Forecast. , 12, 13-35.

Cumby, R., Figlewski, S., \& Hasbrouck, J. (1993). Forecasting Volatility and Correlations with EGARCH Models. Jour nal of Derivatives Winter , 1 (2).

Doornik, J., \& Ooms, M. (2005). Outlier detection in GARCH models. Discussion Paper .

Figlewski, S. (1997). Forecasting Volatility. FINANCIAL MARKETS, INSTITUTIONS AND INSTRUMENTS , 6 (2).

Fox, A. (1972). Outliers in time series. J. R. Stat. , B (34), 350-363.

Franses, P., \& Ghijsels, H. (1999). Additive outliers, GARCH and forecasting volatility. International Journal of Forecasting , 15, 1-9.

GLOSTEN, L. R., JAGANNATHAN, R., \& RUNKLE, D. E. (1993). On the Relation between the Expected Value and the Volatility of the Nominal Excess Return on Stocks. The journal of finance , 48 (5), 1779-1801.

Jarque, C. M., \& Bera, A. K. (1987). A Test for Normality of Observations and Regression Residuals. International Statistical Review , 55 (2), 163172.

Mandelbrot, B. (1963). The Variation of Certain Speculative Prices. The Journal of Business , 36 (4), 394-419.

Nelson, D. (1991). Conditional heteroskedasticity in asset returns: A new approach. Econometrica: Journal of the Econometric Society , 59 (2), 347370. 